\title{
Analysis on Financial Policy of Enterprise and Sustainable Growth
}

\author{
Tao $\mathrm{Wu}^{\mathrm{a},{ }^{* 1}}$, Jinhua Guan ${ }^{\mathrm{b}, * 2}$ \\ ${ }^{a}$ Economics Institute, Northeastern University at Qin huangdao, Qinghuangdao, China \\ ${ }^{b}$ Department of Finance Department, The Environalmental Management College of China, Qinghuangdao,
} China

\begin{abstract}
Excessive growth will constrain enterprise resources, including intelligence, material, and money and so on. The slow growth rate will waste the precious financial resources of enterprise. The average rate of profit will be lower than that of social resources. When the actual sales growth rate is inconsistent with the sustainable growth rate, enterprise should lay emphasis on growth management and adopt appropriate financial policies to keep them consistent. This article analyzes the sales growth from financial perspective and uses financial index to estimate so as to avoid the problems caused by unfavorable growth and eventually to achieve the goal of sustainable growth.
\end{abstract}

Index Terms: Enterprise; Sustainable Growth; Financial Policy

(C) 2012 Published by MECS Publisher. Selection and/or peer review under responsibility of the International Conference on E-Business System and Education Technology

\section{Introduction}

In the development process of enterprise, sales growth is very important. Therefore, lots of enterprises excessively pursue the maximization of sales growth. They obtain the profit growth by increasing price and sales volume. However, sales growth derives from interaction between financial policy and management efficiency. For enterprise, the fast or slow growth is unfavorable to realize the long-term and short-term target of enterprise. Therefore, enterprise should analyze the sales growth from financial angle, and estimate the growth by financial indicators. Thus enterprise takes essential measures to control and adjust sales growth speed and avoid various questions in order to obtain the aim of sustainable growth. in this paper, we analyze the sales growth from financial perspective and uses financial index to estimate so as to avoid the problems caused by unfavorable growth and eventually to achieve the goal of sustainable growth.[1]-[7]

\section{The Sustainable Growth and Its Estimate}

The sustainable growth strategy originally means that the policies for social and economic development are to meet the needs of contemporary without prejudice to future generations in order to ensuring the long-term

* Corresponding author:

E-mail address: ${ }^{* 1}$ Wt0331@ 163.com; ${ }^{* 2}$ Guanjinhua2008@126.com 
and coordinated development of environment and resources. The concept mainly refers to the maximum growth level of enterprise without financial resources exhausting when it is introduced into the development research of enterprise. Generally, the concept can be showed by sustainable growth rate.

Robert. C. Higgins, an American senior financial expert, had published the paper of "Under inflation sustainable rate of increment" in "financial management journal" in 1981, given the equation of sustainable growth rate. Later he systematically expatiate the opinion of sustainable growth rate in the book of Analysis for Financial Management.

The equation of sustainable growth rate is:

Sustainable growth rate $=\mathrm{ROE} \cdot \mathrm{b} /(1-\mathrm{ROE} \cdot \mathrm{b})$

Or

Sustainable growth rate $=$ growth quota of net worth/initial net worth

$$
=\text { change value of shareholders, interest/ initial shareholders, interest }
$$

At above equation, ROE represents the yield of shareholders' interest, which reflects the rate of profit derived from the shareholders' investment, and can be calculated by the following equation:

$$
\mathrm{ROE}=\text { the rate of profit } \times \text { funds turn-over rate } \times \text { lever coefficient(or interest multiplier) }
$$

Where $\mathrm{b}$ represents the rate of retained revenue $=1$-the rate of dividend delivering

\section{Management Principle of Sustainable Growth}

Management principle of sustainable growth means the optimization of growth rate by controlling the growth process.

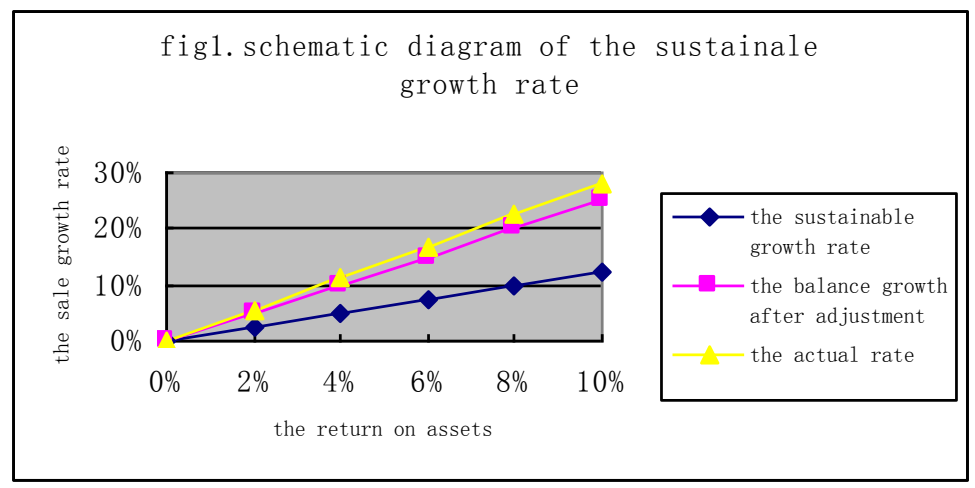

Fig. 1. The sustainable growth rate of the enterprise

To avoid the serious financial question resulting from enterprise quickly growth, the enterprise should take reverse thinking according the equation of sustainable growth rate. That is, the growth rate limit of enterprise is to be defined by the limit of financial policy. For example, if the lever coefficient of an enterprise is 2 , the rate of retained revenue is $60 \%$, the rate of profit and funds turn-over rate can be embodied by return on assets (ROA), the sustainable growth rate of the enterprise is 1.2ROA(as shown in Fig.1). If developing as the speed, 
the enterprise can satisfy the need of growth by cash flow, while can't change the financial policy. Meanwhile, the sustainable growth rate is balance growth rate. If the fact growth rate of enterprise deviates the balance growth rate, which results in adverse or favorable balance of cash. When growth rate exceed the balance rate, the enterprise will has adverse balance of cash. Conversely, the enterprise will has favorable balance of cash. Therefore, the enterprise should define an appropriate balance growth rate according to its relevant financial policy. In practically running process, the enterprise can adjust in good time when deviation appears. For example, the enterprise quickly expanding can get balance growth rate to induce the adverse balance of cash by increasing the rate of retained revenue and lever coefficient.

\section{Enterprise Sustainable Growth Financial Policy}

In order to accomplish the goal of sustainable growth, enterprises which have higher or lower speed contrast with the appropriate sustainable growth must have the different financial police.

\subsection{Rapid growth company}

Rapid growth company refer to the cooperation has real growth faster than sustainable growth. These kinds of firms always focus on the sale growth instead of the financial resources exhausting.

Rapid growth company could adopt four kinds of strategies to meet the challenges of excessive growth. These strategies will be illustrated by the case of HuaTong Company. The annual sustainable sales growth ratio and the annual real sales growth ratio of HuaTong from 2005 to 2009 are shown in table 1.

Table 1. HuaTong Co. 2005 2009 sustainable growth analysis

\begin{tabular}{lccccc}
\hline & $\mathbf{2 0 0 5}$ & $\mathbf{2 0 0 6}$ & $\mathbf{2 0 0 7}$ & $\mathbf{2 0 0 8}$ & $\mathbf{2 0 0 9}$ \\
\hline Profit margin (\%) & 34.2 & 39.6 & 33.1 & 41.8 & 40.4 \\
Subsistence income ratio (\%) & 100 & 100 & 100 & 100 & 100 \\
Gross asset veloci(degree) & 0.2 & 0.2 & 0.3 & 0.3 & 0.3 \\
Lever coefficient(times) & 1.3 & 1.4 & 1.4 & 1.5 & 1.8 \\
Sustainable growth ratio (\%) & 8.9 & 11.1 & 13.9 & 18.8 & 21.8 \\
Real growth ratio (\%) & 53.2 & 36.4 & 46.5 & 49.3 & 40.6 \\
\hline
\end{tabular}

(Data resource: HuaTong Co. 2005 2009 finance report and annotation analysis)

The annual real sales growth ratio of HuaTong much higher than sustainable sales growth ratio. HuaTong increases their asset velocity $50 \%$ and Lever coefficient nearly $50 \%$ to keep their higher real growth ratio.

Four kinds of growth strategies could be adopted to prevent the real growth higher than sustainable growth over a long period of time.

\section{- Stock expansion}

Enterprise could publish new shares to figure out the problem in sustainable growth. The rights capital and credit on loan would provide plenteous fund. But this tactic restricted by capital market mature degree. If the capital market underdeveloped or even not exist, vast cost of transaction must paid. Especially to the small company, no investment bank guarantees to deal with stock expansion affair unless their product very popular in the market.

\section{- Financial lever coefficient increasing and dividend disburse ratio decreasing}

Firms could increase cash resource though the method of financial lever coefficient increasing and dividend disburse ratio decreasing. Debt financing is constrained by the factors such as the optimal capital structure and the risk expectation of loaner. Financial lever coefficient has its limit, the company could not undergo debt 
financing if the limit is broken through, meanwhile the limit of dividend disburse ratio is zero. Shareholders would please to give up their current bonus stock to win much future reward, if they are persuaded to convince that.

\section{- Order transfer}

Companies could adjust their management strategies to control their expand process. Order transfer means that cease such low payoff items to save money to support the new high profit project. The cash pressure originated by continuous expand would decreased by concretely three ways. Firstly, sale the low margins produce items to earn cash. Secondly, abnegate low payoff expand plan to cut down the real growth ratio. Thirdly, abandon clients with poor credits and inventories with low turnover ratio.

\section{- Semi-manufactured goods outsourcing}

Half-finished goods could manufacture by it or purchased by supplier. We argue that outsourcing is a better way to advance the sustained expand ratio than make by itself. Outsourcing could save the capital resources tied up in current assets and fixed assets and relaxed the capital tension eventually. Outsourcing none core competitive activities of capital-intensive is an important strategy to enhance the sustained expand ratio.

\section{- Change sale policy}

The way of change sale policy in growth management include adjust sale price and change credit policy. When enterprise sale growth is too fast to financial resource, enterprise can raise selling price to slow growth. At the same time, raise selling price can enhance production profit rate, and do good to enterprise sustainable growth ratio. on the side, enterprise can deflate credit policy to decrease enterprise sale quantity and practical growth ratio, and speed up cash turn over speed, meet enterprise sustainable growth' demand.

\section{- Enterprise merge}

When enterprise interior improvement can't do efficient growth management, it needs to find partners who deposit lots of financial resource due to too slow growth in capital market. These enterprises generally are in maturate or decline stage, and spend lots of time in investment. This is a double win opportunity to growth too fast or too slow enterprise merge action.

\subsection{Slow growth enterprise means sustainable growth ratio exceed practical growth ratio}

To compare difficulty point produced by insufficient growth, let us analyze enterprise named XuSheng sustainable growth ratio from 2006 to 2009 in Tab2.

Table 2. g enterprise named XuShen sustainable growth ratio analysis from 2006 to 2009

\begin{tabular}{lcccc}
\hline & $\mathbf{2 0 0 6}$ & $\mathbf{2 0 0 7}$ & $\mathbf{2 0 0 8}$ & $\mathbf{2 0 0 9}$ \\
\hline Profit rate (\%) & 1.8 & 3.0 & 5.9 & 6.9 \\
On hand income ratio (\%) & 100 & 100 & 100 & 100 \\
\hline Capital turn over ratio (times) & 1.6 & 1.5 & 1.9 & 1.8 \\
lever coefficient (times) & 2.7 & 3.2 & 2.5 & 2.2 \\
\hline Sustainable growth ratio (\%) & 7.8 & 14.3 & 28.6 & 27.5 \\
Practical growth ratio $(\boldsymbol{\%})$ & 2.8 & 5.3 & 15.4 & 8.2 \\
\hline
\end{tabular}

(Data resource: XuSheng enterprise2006-2009 financial report forms and note analysis )

Enterprise named XuSheng practical growth ratio lower to sustainable growth ratio along with enterprise income ability comeback as shown in table2. In 2008, financial lever ratio fall range exceed $20 \%$ to that of 2007, despite capital turn over ratio increase, cash balance gain fourfold, enterprise sustainable growth indemnificatory buildup.

If enterprise are in growth stage, and slow growth intend to last for long time, then enterprise manager can find enterprise reason of slow growth and method of new growth. In this condition, enterprise manager need 
to analysis enterprise manage process carefully to find and remove enterprise growth restrict factor, at the same time survey market, strength market marketing, exploit market, increase sale growth ratio. If enterprise can't do high growth ratio by oneself, then do other choice. In general, enterprises have three choices, which are established strategy growth, stock repurchase or increase dividends, merge buy growth.

\section{- Established strategy growth}

When enterprise implement long-term strategy, growths' speed is likely to lower than sustainable growth ratio in certain long time. In this condition, enterprise can ignore slow growth' speed, and continue invest to enterprise core produce manage item which are low income, or accumulate resource and wait for strategy middle or high growth come.

\section{- Stock repurchases or increase dividends}

The straight settle idle capital way is stock repurchase or increase dividends to return capital to shareholder, it is simple, but enterprise manager don't like for it shrink manager manage power

\section{- Enterprise merges}

To avoid manage risk, When enterprise growth slow and have idle financial resource, enterprise manager hope to do diversification management. They plan to find cost-effective growth opportunity in great-hearted industry. In capital market, maturate or decline enterprise will search efficient way to make good use of cash, and fast growth enterprise is search for cash to meet growth need. So, fast and low growth enterprise can merge to settle growth manage problem..

\section{Conclusion}

Sustainable growth is important to enterprise long-term development. Too fast or too slow growth will go against enterprise growth and development, so financial should play important role in enterprise development, adopt suitable financial policy initiative to make sure enterprise growth speed close to sustainable growth ratio and have sustainable healthy development.

\section{References}

[1] Fuchu Guo.Yaguang Zheng, "Finance review on sustained development of economy," China Economics publishing company. 2006,pp.105-134, in Chinese.

[2] QiongLi, PingYang, "Influence of sustainable rate on Financial Management, journal of hunan college of finance and economics," vol. 21(5), pp : 43-45, 2005,in Chinese.

[3] Lixia Feng, "Finance analyst," Central South University Publishing House, pp: 219-234, 2004, in Chinese.

[4] Robert.C. Higgins. "Financial Management analyst," Beijing University Publishing House, pp: 83-89, 2003, in Chinese.

[5] Yufeng Lu "Preliminary analysis on enterprise financial strategy based on sustainable rate," Modern Business, vol.27, pp.145,2009, in Chinese.

[6] Tianyi Zhai. ,"Relation between enterprise sustainable rate and sustained economic growth," commercial times, vol.6, pp: 74-75, 2009,in Chinese.

[7] Fei He. ,"Study on financial strategy of enterprise sustainable rate," Thesis of southwestern university of finance and economics.2007, in Chinese. 